Andrew Thomas*

\title{
Three Short Arguments Against Goff's Grounding of Logical Laws in Universal Consciousness
}

https://doi.org/10.1515/krt-2021-0026

Published online November 1, 2021

Abstract: In this paper, I argue that Goff's view that universal consciousness grounds logical laws such as the law of non-contradiction cannot be true on the grounds that we cannot guarantee the classical logic loving nature of universal consciousness that Goff desires in order to ground logical laws. I will present three arguments to show this.

Keywords: universal consciousness, impossible worlds, grounding, logical laws

\section{Introduction}

Goff argues that universal consciousness (UC) can account for the truth of logical laws or put more precisely that UC can ground the law of non-contradiction (LNC) (Goff 2020, p. 117), Goff's focus is on LNC, so that will be my focus too.

In short, Goff argues that UC necessarily obeys classical logic because of its nature and that $\mathrm{UC}$ is 'the clay' of the universe. Thus the universe cannot be formed in such a way that it violates LNC. However, Goff admits that he has no principled reason for us to think that $\mathrm{UC}$ is necessarily logical in the desired way, but this is as good a starting point as any (Goff 2020, fn4). I argue contra Goff that we do have a principled reason to think otherwise. I present three short arguments to show this. The first two are very short; in these, I aim to present straightforward counterexamples which have been mentioned previously in the literature but have potentially gone unnoticed by Goff. My third argument is more detailed, and I think ultimately more problematic for Goff. My view is if there is good reason to think that since there are worlds which differ in physical laws, there are worlds which differ in the logical laws and therefore, neither LNC nor the classical logic loving nature of UC are necessary. By writing this paper I hope to show that many of the general arguments against LNC which have been endorsed by philosophers before me

*Corresponding author: Andrew Thomas, Deparment of Philosophy, Durham University, 50 Old Elvet, Durham DH1 3HN, UK, E-mail: andrew.thomas@durham.ac.uk 
accurately apply to Goff's position and that ultimately his suggestion is untenable because of these objections. In particular my third argument which offers a novel argument against Goff's position and builds on existing literature concerning the nature of LNC. ${ }^{1}$ I also hope to highlight that understanding LNC as something necessary and fundamental to the universe is a potentially ill informed position and contradictions or the possibility of contradictions may be more apparent then originally thought.

The structure of this paper is as follows, in Section 2, I provide the details of Goff's position. Then I present my three arguments against Goff. In Section 3, I argue that at most UC can only ground the laws of certain logics and that the presence of other useful logics is a problem for Goff. In Section 4, I suggest there is a straightforward reason to think we see contradictions at the actual world in artworks. If the examples I highlight are even partly constituted by UC, then their existence undermines the apparent contradiction avoiding nature of UC. In Section 5, I argue against Goff's position in more depth. My general argument is if we accept Goff's position that UC is the clay that makes up the universe, there are worlds built of UC in which LNC does not hold, thus violating the claim that UC cannot be formed in a contradictory way. ${ }^{2}$

\section{Universal Consciousness Grounding Logic}

\subsection{The Logical Constraint}

In Goff's earlier works he claimed that consciousness as a datum places a constraint on metaphysical enquiry (Goff 2017, 2019). This 'consciousness constraint' '.. is the constraint on the metaphysician to account for consciousness in her overall theory of reality' (Goff 2020, p. 109). Goff thinks a similar constraint goes for logic and divides the 'logical constraint' into two aspects.

1 For such general comments concerning LNC see (Priest 1998; Priest, Beali, and Armour-Garb 2006).

2 Some readers might wonder why I have offered three arguments rather than just the final one. For the first two arguments seem to be contained in the last. My motivation for this is as follows: In Goff's paper he seems to think of 'logic' as some fundamental feature of the world. However, I think this is mistaken, 'logics' are more like a tool which can be a used appropriately in different circumstances, argument one speaks to this. Argument two is included in order to show that the belief that there are no contradictions at the actual world is on flimsy ground. Argument three directly responds to Goff's claims and is therefore ultimately the most forceful, it is also an original argument against a particular feature of Goff's argument. 
1. The Metaphysical Aspect-The metaphysician is obliged to postulate entities sufficient to ground the truth of the laws of logic.

2. The Epistemological Aspect-The metaphysician is obliged to account for our knowledge of the laws of logic. (Goff 2020, p. 109)

My focus will solely be on the metaphysical aspect. Goff points out that:

With regards to the metaphysical aspect of the logical constraint, there is strong pressure to hold that the ground of LNC is outside of the contingent universe. For suppose we grounded LNC in some contingent entity or collection of entities $E$. Given $E$ is contingent, there will be at least one possible world, call it $\mathrm{W}$, in which $\mathrm{E}$ fails to exist. But if the ground of LNC does not exist in W, then presumably LNC will not be true in W. (Goff 2020, p. 110)

This for Goff is not the desired outcome; Goff assumes that LNC is true in all possible worlds. He formulates the argument in the following way.

\section{Argument for the Non-Contingency of the Ground of LNC}

1. If the ground of LNC is contingent, then there will be some possible world in which it fails to exist.

2. If there is a possible world in which the ground of LNC fails to exist then there will be a possible world in which LNC is not true.

3. There is no possible world in which LNC is not true.

4. Therefore, the ground of LNC is not contingent.

Goff highlights that based on his argument one might be led towards a 'Platonic view' by which LNC is grounded in an abstract object that necessarily co-exists with any possible universe, but he also notes that there is pressure in the other direction. In order to handle this Goff says 'What we need is something between Platonic heaven that Plato pointed towards and the physical world that was Aristotle's focus. We need an entity that transcends the physical universe and yet is intimately involved with it' (Goff 2020, p. 114). According to Goff, it is UC that plays this important role. ${ }^{3}$

3 The notion of grounding has had a rich literature. Goff does not provide a definition of grounding in the paper under examination. However, in conversation he pointed me towards his 2017 work for his theory of grounding (Goff 2017). Goff defines grounding as 'non-causal explanatory relationship that obtains between facts or other entities' (Goff 2017, p. 41). However, Goff seems to be making the stronger grounding claim that the nature of UC necessities LNC. For more on necessary grounding relations see (Kelly 2013) and for a general discussion on grounding see (Bliss, Kelly and Zalta 2016). 


\title{
2.2 Universal Consciousness
}

Before we get onto how UC is supposed to ground logical laws, it would be helpful to have a brief articulation of what UC is. In short, UC is 'consciousness stripped of phenomenal qualities' (Goff 2020, p. 114). To get a better understanding of UC can best be achieved by way of analogy. According to Goff:

\begin{abstract}
...the relationship between UC and conscious minds is something like the relationship between a lump of clay and individual figures formed by that lump, this is a peculiar kind of clay that can exist without forming any shape at all. And there is another respect in which the clay analogy fails: whilst a hunk of clay that forms a specific cube at a given time must be distinct from the hunk of clay that forms a specific sphere at the time, the universal consciousness from which my mind is formed is numerically identical to the universal consciousness's from which your mind-and every other mind is-formed. (Goff 2020, pp. 114-115)
\end{abstract}

There are lots of arguments against the viability of UC, which Goff does cover and respond to in detail. I will not recap these issues with UC here (Goff 2020, pp. 114-116). If we want to argue effectively against Goff, we cannot merely deny the nature of UC for this would just amount to disagreement from the outset, and mere disagreement is no good argument. We must at least allow for the possibility of UC and argue against Goff's position down the line.

\subsection{How Universal Consciousness Grounds Logic}

For UC to be helpful when it comes to grounding logical laws, it must be understood as a claim about all of modal space (Goff 2020, p. 117). Importantly for Goff's application of UC it must be considered to be a necessarily existent entity, 'and all possible contingents entities are conscious subjects formed, and thereby partially constituted by, universal consciousness' (Goff 2020, p. 117).

To handle the metaphysical aspect, Goff needs further stipulation. He needs to posit that 'universal consciousness has an essentially logical nature, e.g. is essentially such as to not tolerate being formed into contradictory states of affairs. This is just the nature of the clay out of which concrete entities are formed. This postulation entails, given that all possible states of affairs are formed from universal consciousness, that LNC holds in all possible worlds' (Goff 2020, p. 117).

In short Goff's position is that UC has an essential nature in line with the laws of classical logic and as such cannot be formed in a contradictory way. UC is the building material that comprises this world and all possible worlds. It is what comprises the entire universe. Given the conjunction of these theses, it follows that 
LNC holds at all possible worlds since all possible worlds are formed by UC which would not allow itself to be any contradictory way, thus the truth of LNC is grounded in the nature of UC. This is Goff's answer to the metaphysical aspect and essentially how Goff explains the grounding of LNC.

\section{Argument One: Logical Pluralism}

In this section, I argue that Goff's account at most can only ground the laws of some logics and that the presence of other useful logics show there is no reason to privilege classical logic as the one true logic. There are a number of different logics that are used by philosophers for different jobs some of these logics deny the law of LNC and replace it with other laws and axioms which if we were to accept the nature of UC would not be grounded by UC.

More properly put these logics deny explosion, the logical consequence that any arbitrary contradiction entails any arbitrary conclusion. These explosion denying logics have become known as Paraconsistent logics. A logic should be considered paraconsistent 'iff its logical consequence relation ( $\vDash$, either semantic or proof-theoretic) is not explosive' (Priest, Tanaka, and Weber 2018). Goff's footnote four is supposed to handle these worries; however, his point here makes out as if paraconsistent logic is just one logic and that it is an anomaly for his system. However, this is simply not the case. There are a range of paraconsistent logics used for different jobs, in regular and specialised discourse where classical logic was not sufficient. For example, paraconsistent logics have applications in: information change in conversation, development of scientific and computing theories, constitution and other legal documents, descriptions of fictional (and other non-existent objects) and describing counterfactual situations (Priest 2002, p. 299). The existence and usefulness of paraconsistent logics present a problem for Goff. He rules out that the laws of these logics could be grounded by UC. ${ }^{4}$

\section{Argument Two: Contradictions at Actuality}

If we are to believe Goff's description of UC, there would be no contradictions at all. However, there is some reason to think we genuinely see contradictions at the actual world. Priest illustrates this with two examples (Priest 1999). First, Penrose's

4 For the sake of space and because I think my final argument is the most original and forceful I do not provide the details of each paraconsistent logic, for details see (Goff 2020; Priest 2002). 
staircase in which every step of the staircase appears to be above the preceding (in a clockwise direction). However, the point at which one ends is not higher than the starting point. Thus we have both ascended and not ascended. Another example highlighted by Priest is the image Fall, by Akiyoshi Kitaoka. In this image, we see something, both moving and not moving at the same time. What is more these are not the only examples of contradictions occurring at actuality.

If these images are even partly constituted by UC no contradiction should be present, but if Priest is correct, then a contradiction is present, and this is a problem for Goff.

\section{Argument Three: The Contingency of Logical Laws}

In this section, I argue that there is principled reason to think that LNC is not necessary, in the sense that it does not hold at all worlds. In essence, my argument is that if we think that there are worlds which are physically different, then we should think there are worlds which are logically different. I also think that the same argument shows that UC cannot only be bound to favour classical logic. The first step in the argument is to show that there are worlds of non-classical logic (or impossible worlds as they have become known). ${ }^{5}$ The second step is to show that there is good reason to think that impossible worlds are of the same kind as possible worlds. If Goff admits, the possible worlds are classical logic obeying worlds and formed by UC, the impossible worlds which disobey non-classical logic also must be formed by UC thus violating the apparent non-contradiction forming nature of UC and therefore, in turn, undermining the grounds of the necessity of LNC.

\subsection{Step One}

The simplest and one of the most forceful argument I know for impossible worlds is an analogue of Lewis's argument for possible worlds. I do not think we need to

5 I dislike the term 'impossible worlds' for it might push readers to think that these worlds could not be, that they are nothing in the most straightforward sense. I would prefer to call them nonstandard or non-normal worlds since this emphasises the fact that impossible and possible are similar in kind but differ in other ways, for example, the kind of logic that operates there. However, 'impossible worlds' is the moniker this group of worlds have become known by so I will continue with this tradition. 
accept Lewis's genuine realism for the argument to be forceful. However, I do argue that Goff must at least be a minimal realist about possible worlds for his account to have any bite. For if it is the case that UC is the '... clay out of which concrete entities are formed' then possible worlds for Goff must be-at least in part-be formed from this clay, for if they are not and LNC holds at these worlds then that is mere luck and not because of UC doing any grounding work. I do not think this is a point against Goff (nor for him), but I do think it is important to recognise as it ensures the forcefulness of Naylor's argument which comes below. ${ }^{6}$

First, I provide Lewis's argument, then Naylor's argument by analogy.

I believe that there are possible worlds other than the one we happen to inhabit if an argument is wanted, it is this: It is uncontroversially true that things might have been otherwise than they are. I believe, and so do you, that things could have been different in countless ways. But what does this mean? Ordinary language permits the paraphrase: there are many ways things could have been beside the way that they actually are. On the face of it, this sentence is an existential quantification. It says that there exist many entities of a certain description to wit, 'ways things could have been'. I believe that things could have been different in countless ways; I believe permissible paraphrase of what I believe; taking the paraphrase of its face value, I therefore believe in the existence of entities which might be called 'ways things could have been'. I prefer to call them possible worlds. (Lewis 1973, p. 84)

Naylor argues that if we are happy to accept Lewis's argument for possible worlds, then we should accept the same argument for impossible worlds.

Naylor writes:

It is also uncontroversially true that some things might not have been otherwise than they are. The chair that is in fact blue could not have been both blue and red in the same respect and at the same time. I believe, and so do you, that things could not have been different in countless ways. But ordinary language permits the paraphrase: there are many ways things could not have been besides the way that they actually are. On the face of it, this sentence is also an existential quantification. It says that there exist many entities of a certain description, viz., 'ways things could not have been.' I believe permissible paraphrases of what I believe. Taking the paraphrase at face value, I therefore believe in the existence of entities which might be called 'ways things could not have been'. I call them impossible worlds. (Bedford Naylor 1986, pp. 28-29)

If we are happy to admit possible worlds, then we ought to be happy to admit impossible worlds. Goff relies on possible worlds to get his argument going and thus should also be happy to admit impossible worlds too. At this stage, some readers might be asking what exactly impossible worlds are. To answer that

6 Kiourti, provides additional motivation for impossible worlds (Georgia Kiourti 2019), but Naylor's argument has been selected here because if one is happy to accept possible worlds to explain contingency, then they should also be happy to accept impossible worlds. 
question, I turn to Berto and Jago who provide a comprehensive analysis (Berto and Jago 2019, pp. 31-32).

1. Impossible ways: One way to understand impossible worlds is as impossible ways. We might understand impossible worlds as similar to possible worlds (Berto and Jago 2019, p. 31). Along the lines of 'If possible worlds are ways things could be, then non-normal or impossible worlds are ways things could not be.' The thought behind this conception of impossible worlds is that everything is possible. However, there are somethings which cannot happen. The ways the world couldn't be are impossible world's. Yagisawa thinks of impossible worlds like this (Yagisawa 1988).

2. Logic violators: We might also just understand impossible as worlds where the laws of logic fail. Of course, this conception depends on what we take the laws of logic to be. Berto and Jago characterise this view in the following way 'Given some logic $L$, an impossible world with respect to the $L$-laws is one in which some of those laws fail to hold' (Berto and Jago 2019, p. 31). Priest says, 'After all, we seem to envisage just such worlds when we evaluate conditionals such as "if intuitionist logic were correct, the law of identity would fail" (false). Even if one is a modal realist, why should there not be such worlds?' (Priest 2008, pp. 171-172)

3. Classical logic violators: A third way of understanding impossible worlds is to think of them as a classical logic violator. If we think that the laws of logic are the classical ones, then this gives the same result as the previous definition. However, if we think otherwise 'A world complying with intuitionistic logic, but where instances of Excluded Middle fail, will be impossible in this third sense' (Berto and Jago 2019, p. 32).

4. Contradiction-realizers: The final way to understand impossible worlds is one where contradictions hold, that is to say, worlds at which sentences that take the form $A$ and $\neg A$ hold, violating LNC.

Whichever conception of impossible worlds we opt for is problematic for Goff, each would undermine his position, either the contradiction avoiding nature of UC (in 1, 3 , 4) or directly undermine the necessity of LNC (in 2 and 3).

\subsection{Step Two}

One way Goff might try and avoid my charge is to suggest that UC is only the material that comprises possible worlds and that impossible worlds are wholly different in their composition. Not only would this be ad hoc, but there is a 
principled reason to think impossible worlds and possible worlds are of the same kind. Priest expresses this idea clearly:

\begin{abstract}
As far as I can see, any of the main theories concerning the nature of possible worlds can be applied equally to impossible worlds: they are existent non-actual entities; they are nonexistent objects; they are constructions out of properties and other universals; they are just certain sets of sentences ... There is, as far as I can see no cogent (in particular, non-question begging) reason to suppose there is an ontological difference between merely possible and impossible worlds. (Priest 1997, pp. 580-581)
\end{abstract}

If Priest is correct, then there is a principled reason to think that our theory of possible worlds should extend to impossible worlds. If Goff has to admit impossible worlds on the grounds I have presented here, his theory for grounding LNC is in trouble.

\title{
6 Conclusions
}

In this paper, I have presented three arguments against Goff's theory of grounding logical laws in UC. The first two arguments are straightforward counterexamples. The third argument is more substantial. I argued that if we invoke possible worlds to make sense of contingencies in physics, then we also ought to think that there are worlds that are other ways logically, these we call impossible worlds. I have also shown that we should think that impossible worlds and possible worlds-no matter what our theory of them is-should be of the same kind. If this is true than Goff's argument for grounding LNC in UC is undermined. For either, there are worlds made up of UC that violate its apparent contradiction hating nature, or there are worlds which show that LNC is not necessary.

\section{References}

Berto, F., and M. Jago. 2019. Impossible Worlds. Oxford: Oxford University Press.

Bedford Naylor, M. 1986. “A Note on David Lewis' Realism About Possible Worlds.” Analysis 46 (1): 28-9.

Bliss, R., and K. Trogdon. 2016. “Metaphysical Grounding”. In: The Stanford Encyclopedia of Philosophy, edited by E. N. Zalta. Stanford: Metaphysics Research Lab, Stanford University, 2016.

Georgia Kiourti, I. 2019. "An Excess of Dialetheias: In Defence of Genuine Impossible Worlds". In Dialetheism and its Applications, edited by A. Rieger, and G. Young, 81-100. Berlin: Springer International Publishing.

Goff, P. 2017. Consciousness and Fundamental Reality. Oxford: Oxford University Press. 
Goff, P. 2019. Galileo's Error: Foundations for a New Science of Consciousness. New York: Pantheon.

Goff, P. 2020. "Universal Consciousness as the Ground of Logic." In Panentheism and Panpsychism, 107-22. London: Rider.

Kelly, T. 2013. “Grounding: Necessary or Contingent?” Pacific Philosophical Quarterly 94 (4): 465-85.

Lewis, D. K. 1973. Counterfactuals. Oxford: Blackwell.

Priest, G. 2008. "An Introduction to Non-Classical Logic: From if to is.” In Cambridge Introductions to Philosophy, 2nd ed. Cambridge: Cambridge University Press.

Priest, G. 2002. “Paraconsistent Logic.” In Handbook of Philosophical Logic, 287-393. Dordrecht: Springer.

Priest, G. 1999. "Perceiving Contradictions.” Australasian Journal of Philosophy 77 (4): 439-46.

Priest, G. 1997. "Sylvan's Box: A Short Story and Ten Morals.” Notre Dame Journal of Formal Logic 38 (4): 573-82.

Priest, G. 1998. "To Be and Not to Be-That is the Answer. On Aristotle on the Law of NonContradiction." History of Philosophy \& Logical Analysis 1. https://doi.org/10.30965/ 26664275-00101007.

Priest, G., J. C. Beali, and B. Armour-Garb. 2006. The Law of Non-contradiction: New Philosophical Essays. Oxford: Clarendon Press.

Priest, G., K. Tanaka, and Z. Weber. 2018. "Paraconsistent Logic”. In The Stanford Encyclopedia of Philosophy, edited by E. N. Zalta. Stanford: Metaphysics Research Lab, Stanford University. Yagisawa, T. 1988. “Beyond Possible Worlds.” Philosophical Studies 53.2: 175-204. 